\title{
Macroseismic intensity hazard maps for Italy based on a recent grid source model
}

\author{
${\text { Pasquale } \text { Cito }^{1} \cdot \text { Eugenio Chioccarelli }}^{2}$ (D) / Iunio lervolino ${ }^{1}$ (D)
}

Received: 19 July 2021 / Accepted: 13 January 2022 / Published online: 29 January 2022

(c) The Author(s) 2022

\begin{abstract}
Seismic hazard maps from probabilistic seismic hazard analysis or PSHA collect, at different sites, the values of the (site-specific) ground motion intensity measures of interest that, taken individually, have the same exceedance return period. For large-scale analyses, a widely used intensity measure is the macroseismic $(M S)$ intensity, that provides an assessment of the earthquake effect based on the observed consequences in the hit area. Hazard maps can be developed in terms of $M S$ intensity, and some examples exist in this respect. In the case of Italy, the last $M S$ hazard map is based on the same seismic source model (known as MPS04) adopted to derive the design seismic actions of the current building code, a study dating more than ten years ago. It provides results in terms of countrywide Mercalli-Cancani-Sieberg (MCS) intensity level with 475 years return period. This short paper presents and discusses MCS probabilistic seismic hazard maps for Italy based on a recent grid-seismicity source model, herein named MPS19, synthetizing the large effort of a wide scientific community. The results, which are obtained by means of classical PSHA, are given in the form of maps referring to the 475 years return period, and also others of earthquake engineering interest. Moreover, it is discussed that the return period does not univocally identifies the $M S$ intensity because, although $M S$ is, by definition, a discrete random variable, it is modelled, in a given earthquake, by means of a normal distribution, that is, treated as continuous. Thus, the maps of the minimum return period causing the occurrence or exceedance of different MCS intensities are also provided. Finally, the comparison between the 475 years return period hazard map presented and the one which is currently the point of reference in Italy, that is, computed using MPS04, is briefly discussed. All the computed maps are made available to the reader as supplemental material.
\end{abstract}

Keywords Probabilistic seismic hazard analysis · Mercalli-Cancani-Sieberg scale · Earthquakes · MPS19 - MPS04

Iunio Iervolino

iunio.iervolino@unina.it

1 Dipartimento di Strutture per l'Ingegneria e l'Architettura, Università degli Studi di Napoli Federico II, Naples, Italy

2 Dipartimento di Ingegneria Civile, dell'Energia, dell'Ambiente e dei Materiali, Università degli Studi Mediterranea di Reggio Calabria, Reggio Calabria, Italy 


\section{Introduction}

Macroseismic $(M S)$ intensity provides a proxy for the impact of an earthquake based on its implications (macroscopically) observed on the affected communities, built environment and structures (e.g., Grünthal 1998). Different $M S$ intensity scales exist (see Musson et al. 2010, for an overview); in general, they consist of grades, identified by ordinal numbers, that differ each other for the earthquake effects that they describe. Although site-specific ground motion intensity measures (IMs) are recognized far more appropriate to characterize earthquakes in the case of analysis and design of a specific structure (e.g., CEN 2004; C.S.LL.PP. 2018) at the construction site, MS intensity is still widely used. For example, right after an earthquake, ShakeMap (Wald et al. 1999a) elaborates the map of $M S$ intensity for the hit area (e.g., Michelini et al. 2019), which may be used for rapid loss assessment. Also, $M S$ intensity may serve to express the vulnerability of existing structures in an area of interest, based on empirical observations (e.g., Giovinazzi and Lagomarsino 2004). Furthermore, in those areas where the seismic monitoring network is sparse or even absent, the observed $M S$ intensity can be used to infer ground motion IMs (e.g., peak ground acceleration; Faenza and Michelini 2010; Gomez-Capera et al. 2020) or to estimate the occurred event magnitude (e.g., Sibol et al. 1987; Azzaro et al. 2011). The Italian seismic catalog, so-called Catalogo Parametrico dei Terremoti Italiani or CPTI (Rovida et al. 2020), contains information, such as magnitude and location, about earthquakes occurred from $1000 \mathrm{AD}$ to the end of 2017, most of which are retrieved based on macroseismic intensity estimates (i.e., effects assessed according to the historical evidences as provided by dedicated studies; e.g., Boschi et al. 2000) being no instrumental data available at the time of occurrence. The first earthquake of the catalog for which early instrumental data are available dates back to 1918 (Sandron et al. 2014) but, until the second half of sixties of the last century, the majority of the earthquakes' magnitude estimations are based on historical information.

For all the cited reasons, it may be worth to compute countrywide probabilistic maps, for fixed exceedance return periods $\left(T_{r}\right)$, in terms of $M S$ intensity, especially for countries, such as Italy, where most of the built environment is very slowly renovated, to say the least. Note that such maps probabilistically describe earthquake consequences, then they could be also seen as risk maps; however, they are usually identified in literature (and hereafter) as hazard maps. On the other hand, if the required risk metric is the damage state of a specific structural typology, the macroseismic intensity hazard needs to be combined with specific vulnerability models, that is, damage probability matrices (see, for example, Iervolino et al. 2015, among others).

In fact, macroseismic hazard assessment studies for Italy have been proposed in the past by Slejko et al. (1998) and Albarello et al. (2000). They used the source model of Meletti et al. (2000) and derived seismicity rates from the earthquake catalog of Camassi and Stucchi (1997). A few years later, another study, dealing with the hazard assessment in terms of $M S$ intensity at the national scale, was published by Gomez Capera et al. (2010). It used the models that, still at the time of writing this paper, are at the basis of the hazard assessment, commonly named as MPS04, which is adopted by the current Italian building code and is considered as the reference $M S$ intensity hazard assessment study for Italy. All the cited works refer to the Mercalli-Cancani-Sieberg (MCS; Sieberg 1930) scale, and present hazard maps collecting, at the national scale, the MCS intensities with ten percent probability in fifty years of occurring or being exceeded, that is 475 years $(y r)$ return period. 
All the hazard maps provided in the cited studies were computed by implementing the classical probabilistic seismic hazard analysis or PSHA framework (e.g., Reiter 1990; Mc Guire 2004). Site-specific PSHA first requires to identify the seismic sources in the region of interest and to characterize them in terms of mean annual number (i.e., the rate) of earthquakes (mainshocks, in fact) above a minimum magnitude (M) of interest, and magnitude distribution given the occurrence of one earthquake event (e.g., Gutenberg and Richter 1944). Finally, (at least) one ground motion prediction equation (sometimes referred to as attenuation relationship) is necessary to model, for any possible earthquake magnitude and location on the source, the probabilistic distribution of the ground motion intensity at the site of interest. The characterization of the sources is based on the available information, historical or instrumental, about past earthquakes, which are typically collected in the earthquake catalogs.

In fact, it is to mention that there are methodologies, alternative to classical PSHA, that may be employed to assess seismic hazard in terms of $M S$ intensity. For example, with reference to Italy, Mucciarelli et al. (2000) and Albarello et al. (2002) provide a countrywide macroseismic hazard assessment profiting of the so-called site approach (Magri et al. 1994). The input of the analysis is defined for each site individually, and consists of a catalog collecting local macroseismic data; e.g., observations according to documentary sources or estimations by means of attenuation relationships. Gomez Capera et al. (2010) compare the results obtained using the site approach to those obtained by means of PSHA.

When PSHA is performed in terms of $M S$ intensity, the implicit assumption is that the resolution of the assessment is such that the effects at a given location, identified by a point (i.e., a longitude-latitude pair) in the analysis, represent the large-scale effect on the built environment at that location. Moreover, the earthquakes magnitude distribution characterizing the seismic sources can be replaced by the distribution of the epicentral intensity $\left(I_{0}\right)$, that is directly related to the historical information provided by the seismic catalogs. Indeed, for a given earthquake, $I_{0}$ is generally assumed as the largest $M S$ intensity level observed in the epicentral area of the seismic event (e.g., Gruppo di Lavoro 2004). Alternatively, if a source model is already available in term of magnitude distribution, it is also possible to convert each magnitude value into the expected (i.e., not the observed) value of the $M S$ intensity at the epicenter, $I_{e}$ (e.g., Albarello et al. 2007). Regardless of whether the input is in terms of $I_{0}$ or $I_{e}$, once the propagation model for $M S$ intensity is chosen (e.g., Ambraseys 1985), the PSHA allows to compute, for a given point, a $M S$ intensity value with a given return period and, extending the analysis to a grid of points, the sought map of $M S$ intensity values characterized by the same return period can be computed; this is despite the fact that $M S$ intensity is defined by means of discrete grades, and some issues may be raised in this respect.

Recently, a set of new seismic hazard models for Italy, named MPS19, was developed as a possible update of the previous source model for the country (Meletti et al. 2021; Visini et al. 2021). The objective of the simple study presented herein is to discuss the seismic hazard assessment for Italy in terms of $M S$ intensity, considering the MCS scale and adopting a source model, not coincident with, yet based on, MPS19 (and retaining its name herein). Four hazard maps, referred to as IMPS19, derived via classical PSHA, are discussed, that is, those showing the $M S$ intensity with return periods equal to 50, 475, 975 and $2475 y r$, corresponding to $63 \%, 10 \%, 5 \%$ and $2 \%$ exceedance probability in $50 y r$ (a typical exposure time in earthquake engineering), respectively.

The remainder of the paper is structured such that the basics of PSHA are recalled, first. After describing the source and the propagation models used in the analysis, the hazard maps for the four selected return periods are presented. Subsequently, for each MCS grade, 
the lowest return period causing its occurrence or exceedance is mapped to discuss some issues deriving from the fact that attenuation relationship models the $M S$ intensity as a continuous random variable. Finally, the IMPS19 hazard map for $T_{r}=475 \mathrm{yr}$ is briefly compared to the counterpart provided of Gomez Capera et al. (2010), referred to as IMPS04. Some final remarks close the study. Hazard maps developed in this study are provided as supplemental material.

\section{Methodology}

This section describes the way in which PSHA is implemented in the case the location of interest is affected by $s$ point-like seismic sources and the seismicity of each source is characterized in terms of $I_{e}$. The analysis ultimately provides the (usually annual) rate of earthquakes that cause $M S$ intensity larger than a certain threshold ( $m s)$ at the location, indicated as $\lambda_{M S>m s}$, as per Eq. (1):

$$
\lambda_{M S>m s}=\sum_{k=1}^{s} \sum_{j=1}^{n} v_{k, j} \cdot P\left[M S>m s \mid I_{e}=i_{e, j}, R=r_{k}\right] .
$$

The exceedance rate is the reciprocal of the exceedance return period. The equation is written assuming that, for each source, seismicity is defined in terms of rate of earthquakes associated to bins, say $n$ in number, of $I_{e}$. Index $k=\{1,2, \ldots, s\}$ identifies each of the sources affecting the seismic hazard at the location of interest and $v_{k, j}$ is the rate of earthquakes, with a specific epicentral intensity $I_{e}=i_{e, j}, j=\{1,2, \ldots, n\}$, occurring at the $k$-th source. The term $P\left[M S>m s \mid I_{e}=i_{e, j}, R=r_{k}\right]$, provided by the propagation model, denotes the conditional probability that $M S$ is larger than $m s$ given that the considered location is subjected to an earthquake with $I_{e}=i_{e, j}$ and that the epicentral distance from the $k$-th source is $R=r_{k}$.

It should be noted that propagation models usually consider $M S$ as a continuous random variable (RV), although macroseismic scales are usually discrete. This is an issue that typically arises with the analysis of macroseismic data for developing propagation models or also relationships between $M S$ intensity and other ground motion parameters (e.g., Wald et al. 1999b; Faenza and Michelini 2010). In PSHA calculations, threating $M S$ as continuous RV allows to obtain a unique $M S$ value for any return period of interest. A side effect is that, when hazard maps are presented discretizing the $M S$ intensity in accordance with the MCS scale, at a given grid point, the same $M S$ intensity could be associated to different return periods. Due to this issue, the maps of the minimum return period associated to each $M S$ intensity grade are also discussed in the following.

\section{Input models}

Recently, a new seismic hazard assessment for Italy, considering a large set of pseudospectral accelerations as the ground motion IM, has been released by Meletti et al. (2021). PSHA is developed via ninety-four seismic source models weighted according to statistical performances in describing the earthquake occurrences and taking into account an experts' elicitation process (Visini et al. 2021). The ensemble of the models are combined, via a logic tree approach, with a set of selected ground motion prediction 
equations (Lanzano et al. 2020). Thus, such a seismic model results in about six-hundred branches of the logic tree. (With respect to the specific purposes of the analyses herein discussed, it must be noted that the several seismic source models in the logic tree are characterized by methodologies, such as geodetic data, which do not allow a direct source parametrization in terms of $M S$ intensity.)

The direct application of this complex model is complicated, so that reproducibility of results is impaired, as it often happens for recent PSHA studies. In fact, to address these issues, a relatively easy-to-implement weighted average grid-seismicity model was derived from the ensemble of the logic tree, by the same working group (details are provided in Chioccarelli et al. 2021). It is made of a grid of about eleven thousand point-like seismic sources covering the whole national territory and the surrounding areas. For each point, seismicity is defined in terms of annual rate of earthquakes per moment magnitude bins (i.e., the activity rates), forty-six in number, the width of which is set to 0.1 . The central value of the lowest magnitude interval is M4.5 across all Italy. The highest magnitude bin, with rate larger than zero, is centered at M9 for about the $85 \%$ of the sources, and at M8.3 for the others. Finally, the probabilistic distribution of the style-of-faulting is defined for each point-like source. Hereafter, this source model is referred to as MPS19.

To develop PSHA in terms of $M S$ intensity using the MPS19 model, which is in terms of magnitude, the propagation model of Pasolini et al. (2008) was chosen. It allows to convert the seismicity rates for magnitude classes into seismicity rates in terms of epicentral intensity $I_{e}$. This means converting the magnitude bin central value into $I_{e}$ according to the semi-empirical relationship of Albarello et al. (2007), and the rate of the magnitude bin is attributed to the obtained (converted) intensity. The conversion model considers $I_{e}$ as a continuous variable, thus, for each bin, the converted value was limited to twelve; i.e., the largest possible MCS grade. The propagation model also assumes that the $M S$ intensity at the grid point of interest, in terms of MCS, is normally distributed, conditional on the epicentral distance and $I_{e}$. It follows that the $M S$ intensity is treated as a continuous RV, although it is, by definition, discrete. More specifically, the relationship between $M S, I_{e}$ and $R$ is given by Eq. (2):

$$
M S=I_{e}-0.0086 \cdot\left(\sqrt{R^{2}+3.91^{2}}-3.91\right)-1.037 \cdot\left(\ln \sqrt{R^{2}+3.91^{2}}-1.364\right)+\sigma \cdot \varepsilon,
$$

where $\sigma \cdot \varepsilon$ is a normally distributed $\mathrm{RV}$, with zero mean and $\sigma$ standard deviation that is equal to 0.87 and represents the residual of $M S$ at the considered point, given $R$ (in $\mathrm{km}$ ) and $I_{e}$. In the study presented herein, the model was applied within its definition range of epicentral distances, that is, $0-300 \mathrm{~km}$.

As shown, the model's covariates are $I_{e}$ and $R$, which means that the model does not allow to account in the analysis for the style of faulting, as other propagation models for Italy do (e.g., Gomez Capera 2007). However, to be employed within the PSHA, these models require the input in terms of $I_{0}$ (in lieu of $I_{e}$ ), that, as mentioned, is not available for the source model used in this study.

In Fig. 1, the MPS19 model is represented in terms of annual rates of $I_{e}$ larger than four values. (It should be noted that associating a value of $I_{e}$ to an earthquake with the epicenter in the sea could appear meaningless according to the definition of $I_{e}$. However, in the context of PSHA, $I_{e}$ is a magnitude-equivalent measure required to apply Eq. (2)).

The rates tend to be larger in north-eastern Italy, along the Apennine mountain chain and in eastern Sicily. It can be observed that the largest annual rate corresponding to $I_{e} \geq 6$ 


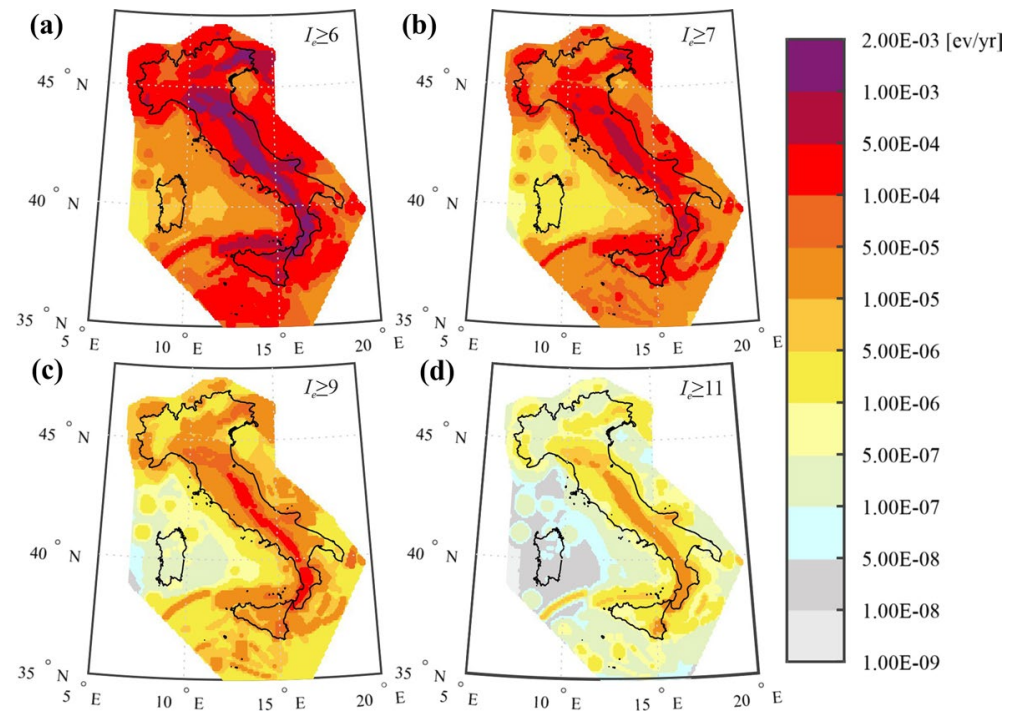

Fig. 1 Maps of the annual rates of earthquakes for the grid-seismicity source model, considering epicentral intensities, in terms of $I_{e}$, equal to or larger than 6 (a), 7 (b), 9 (c) and 11 (d)

(Fig. 1a) is about 2E-03 events per year, whereas it is about 8E-04 events per year for $I_{e} \geq 7$ (Fig. 1b). Considering $I_{e} \geq 9$ (Fig. 1c) and $I_{e} \geq 11$ (Fig. 1d), the largest rates are about $1.4 \mathrm{E}-04$ and $2.9 \mathrm{E}-05$ events per year, respectively.

PSHA in terms of macroseismic intensity using this source characterization was performed via the REASSESS software (Chioccarelli et al. 2019), which implements the above discussed source and propagation model.

\section{Results}

To help the discussion of the results presented in this section, it is worth recalling that grades from I to $\mathrm{V}$ represent earthquakes that may be felt by human beings but not producing structural damage. The seismic damage, in macroseismic terms, observed on structures is taken into account by grades from VI onwards. Indeed, according to the definition of the MCS scale, degree VI (strong earthquake) corresponds to small cracks in buildings, whereas MCS VII (very strong) denotes significant cracks and falling chimneys. Grades VIII (severe) and IX (destroying) represent the partial and complete collapse of some buildings, respectively, whereas MCS X (completely destroying) refers to earthquakes that cause collapse of most buildings in the hit area. Grades XI and XII do not have differences in terms of the observed damage on structures, being both indicative of the destruction of entire urban settlements. It may be interesting to note that the maximum $M S$ intensity reported so far in Italy is X-XI, according to the latest version of CPTI.

The IMPS19 hazard maps, computed considering a grid of about ten-thousands points and four return periods, that are 50, 475, 975 and $2475 y r$, are reported in Fig. 2. The maps are represented using a continuous color scale, in accordance with the hypothesis of continuous RV adopted by the propagation model to describe the $M S$ intensity in one seismic event. On the other hand, in order to comply with the discrete character of the MCS scale, 

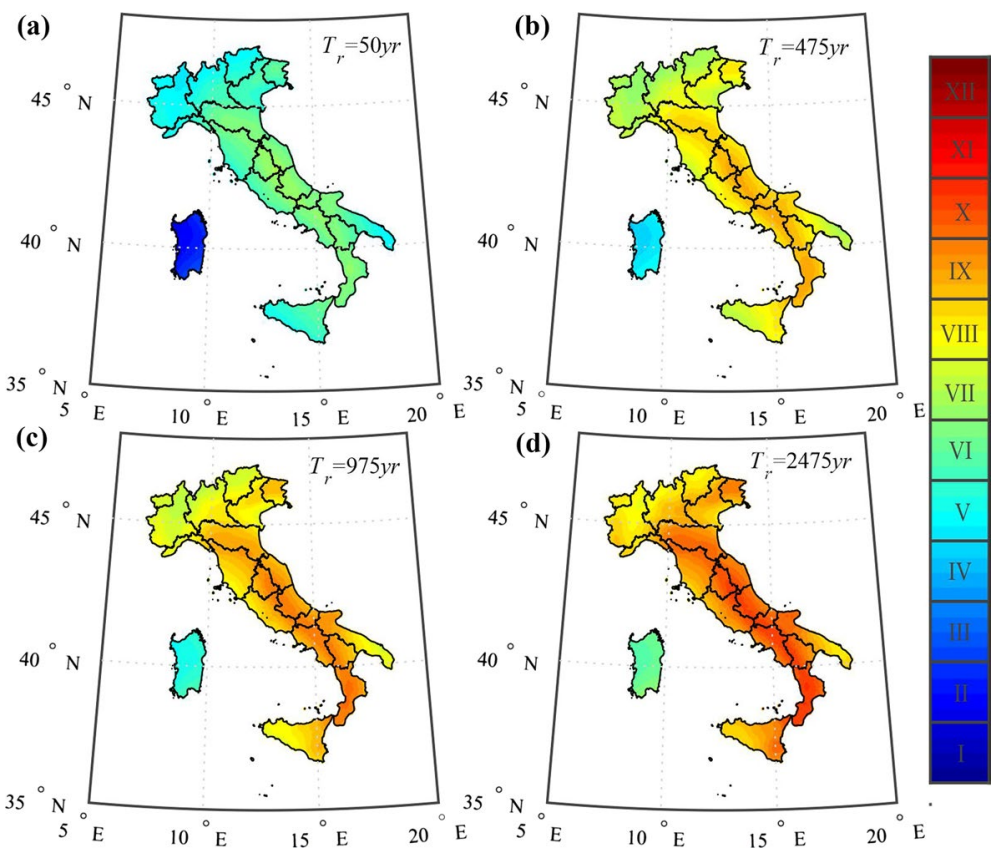

Fig. 2 PSHA maps in terms of MCS intensity with four return periods from 50 to $2475 \mathrm{yr}$

most of the previous works dealing with PSHA in $M S$ intensity present hazard maps by rounding the intensity value to the closest integer (it is a common procedure in relevant literature; e.g., Gomez Capera et al. 2010). Herein, both the continuous and discrete scale are considered to present the results: more specifically, the interval for a certain grade, say $y$, contains the shades pertaining to the intensities between $y-0.5$ and $y+0.5$. It follows that the discrete values in each map of the figure are defined as the grades that, at the points of the considered grid, are observed or exceeded with the selected return period.

It can be observed that the pattern of each hazard map is somehow similar to that of the maps in Fig. 1, as expected. More specifically, for each return period, it is found that, apart from Sardinia, whose hazard is comparatively lower with respect to the inland Italy and Sicily, the grid points with the lowest MCS grade are in the northwest area of the country and part of Apulia (southeast Italy) and western Sicily; also, relatively moderate-to-high intensity grades are found in eastern Sicily, coastal areas and northeast Italy, whereas the locations with the largest MCS grade are along central and southern Apennine mountain chain.

For $T_{r}=50 y r$, the lowest grade across inland Italy (i.e., neglecting Sardinia) is equal to IV, even if the fraction of the country corresponding to such a grade is almost negligible. With reference to the same return period, MCS equal to or larger than V and VI is found in about the $30 \%$ and $60 \%$ of the territory, respectively. The largest grade for $T_{r}=50 \mathrm{yr}$ is MCS VII, and it pertains to a relatively small area, in central Italy, covering about 5\% of the national territory. With reference to $T_{r}=475 \mathrm{yr}$, the lowest MCS grade across the inland country is VI; however, it pertains to an area with negligible extension. The largest grade with $475 y r$ return period is MCS IX, and it is found in the most hazardous area of Italy; i.e., in central and southern Italy, covering about $15 \%$ of the considered grid points (taken individually). Looking at intermediate grades, MCS VII and VIII correspond to 

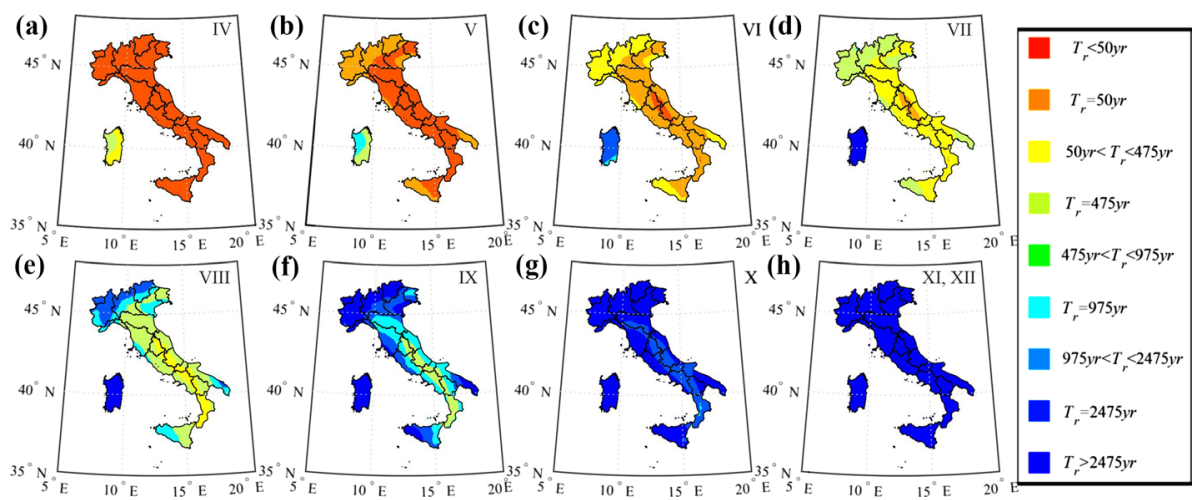

Fig. 3 PSHA maps of the lowest return period of the earthquakes causing MCS grades equal to or larger than specific values

$30 \%$ and $44 \%$ of the points, respectively, including almost the whole northern Italy, coastal areas and Sicily. For $T_{r}=975 \mathrm{yr}$, MCS VII corresponds to $13 \%$ of the grid, which refers to northern Italy. With reference to the same return period, grade equal to or larger than VIII and IX is associated to about $37 \%$ and $41 \%$ of the grid nodes, respectively, whereas the largest MCS is equal to X, yet it is found for a few points in southern Italy, covering about $5 \%$ of the grid. Finally, referring to $T_{r}=2475 \mathrm{yr}$, grade equal to or larger than VIII, IX and X corresponds to about $27 \%, 40 \%$ and $26 \%$ of the grid points respectively, whereas the lowest across all the inland country is VII, yet it corresponds to a small area (i.e., lower than $1 \%)$.

\subsection{Maps of the lowest return period associated to each MCS grade}

As it was already anticipated, rounding the $M S$ intensity level, for one return period, to the closest integer (i.e., the MCS grade) may arise an issue. In fact, at a given grid point, although the hazard result for one return period is different from that associated to another return period, being the $M S$ intensity considered as a continuous RV according to Eq. (1), it may happen that they are both rounded to the same integer. Thus, it cannot be warranted that the MCS grade at one point of the grid monotonically increases with the increasing of $T_{r}$. The consequence is that the hazard maps for two different return periods may show, at the same location, the same MCS grade. To give an example, Fig. 2b, c show that a fraction of northern Italy is classified as MCS VII for both $T_{r}=475 \mathrm{yr}$ and $T_{r}=975 \mathrm{yr}$; the same, yet in different regions of Italy, also happens for other MCS grades. In other words, the discrete character of the MCS scale implies that the association of the $M S$ intensity for a given return period to one point is not unique, as happening for typical ground motion $I M s$ instead. For this reason, it may be also useful to provide an alternative representation of hazard results with respect to the one in Fig. 2. Thus, Fig. 3 shows, for each grid point and MCS grade, the lowest associated return period: panels from (a) to (d) pertain to MCS from IV to VII, whereas panels from (e) to (h) refer to MCS from VIII to XII. The color scale in the figure is discrete because each map refers to one MCS grade and is intended to show, for any point in Italy, the lowest associated return period among the four considered so far. Moreover, if, for a given node of the grid, the $T_{r}$ associated to the MCS grade does 

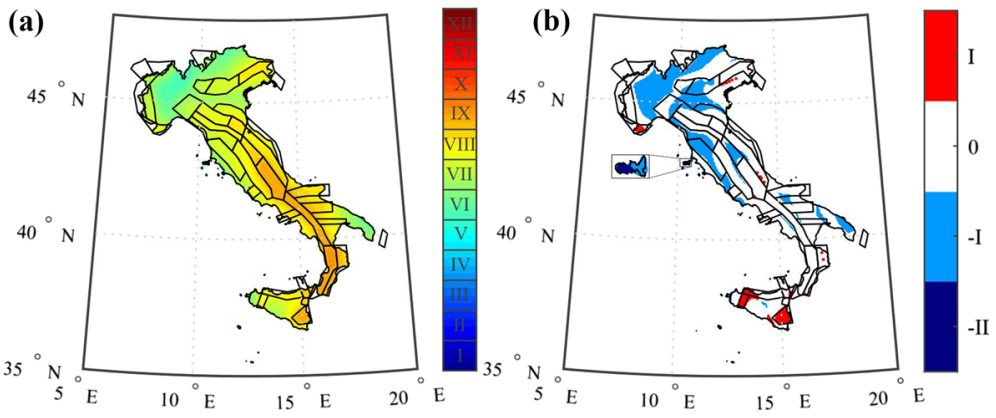

Fig. 4 PSHA map in terms of MCS intensity with 475 yr return period according to IMPS04 (a) and absolute difference with respect to IMPS19 (b)

not contain any of those considered in Fig. 2, the color in the map is representative of the interval of return periods as defined in the legend of the figure.

The maps in the figure reveal that the earthquakes with MCS equal to or larger than IV and $\mathrm{V}$ (i.e., not damaging for structures) are relatively frequent across the whole inland Italy, being the lowest return period equal to or smaller than $50 y r$ anywhere. Conversely, those events classified as capable of destroying entire urban settlements, that is, grade XI and XII, are relatively rare, being their (lowest) return period even longer than $2475 \mathrm{yr}$ anywhere in Italy. Results are less homogenous for MCS from VI to X. In fact, in each of the panels from (c) to (g), the lowest return period causing occurrence or exceedance of the grade declared in the map tends to be lower along the central and southern Apennine mountain chain: this is expected, being this area characterized by the largest seismic hazard, as discussed in the previous section. Accordingly, in the same area, destroying (IX) and completely destroying earthquakes (X) have return period equal to 475 and $2475 y r$, respectively. The low-to-moderate seismic hazard regions are identified, in each panel, by larger return periods: to give an example, in northern Italy and coastal areas, MCS equal to or larger than X has a return period longer than $2475 \mathrm{yr}$.

\subsection{Comparison with MPS04 MCS hazard map}

As discussed, Gomez Capera et al. (2010) provide a national hazard map, in terms of MCS, considering a return period of $475 y r$. Such a map, herein indicated as IMPS04, is considered as a reference. In fact, as recalled above, the PSHA study was developed considering the same input and calculation procedure used for the seismic hazard assessment of Italy, denoted as MPS04, that is at basis of the current Italian building code (Stucchi et al. 2011). It relies on a source model featuring thirty-six areal source zones and no background seismicity. Intensity attenuation was modelled by means of regional propagation models which allow to account for the predominant rupture mechanism of the sources of Meletti et al. (2008). A logic tree accounting for alternative models of catalogue completeness, seismic parameters of the sources and propagation models was also considered; herein, the median map resulting from the logic tree is considered. The hazard map, whose data were provided by C. Meletti (personal communication, April 2021) is shown in Fig. 4a, together with the source zones that it is based on. 


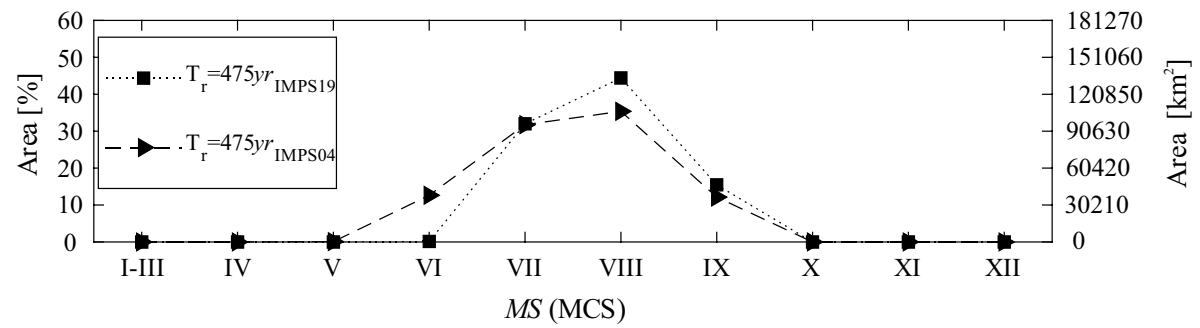

Fig. 5 Fraction of Italy, in relative and absolute terms, associated to the different MCS grades according to IMPS04 and IMPS19

Its pattern is quite similar to that of the map based on the grid-seismicity source model, for the same return period, shown in Fig. 2b. This is even more evident when comparing results considering the discrete MCS scale, as shown in Fig. 4b. More specifically, the map shows the absolute differences between IMPS04 results, in terms of MCS, and those denoted as IMPS19. It is shown that, in a significant fraction of Italy, which extends for about $65 \%$ of the territory (Sardinia Island is not taken into account, as IMPS04 does not give hazard results for the region) and includes almost all the MPS04 areal source zones, the MCS grade from Fig. 4a is the same as in Fig. 2b. The map of the differences also reveals that the differences are limited to one grade (except part of the small Giglio Island off-shore Tuscany, where the difference goes up to two grades, as shown in the figure). More specifically, the results of IMPS04 are lower than those of IMPS19 in the areas outside the source zones of Meletti et al. (2008) (e.g., northern Italy and Apulia region) and also in small areas enclosed by the MPS04 zones found in northern and central Italy; overall, these areas cover about $33 \%$ of the country. Finally, in the remaining $2 \%$ of Italy, which includes the grid points enclosed by the MPS04 zones found in a small fraction of northwestern Italy and in western Sicily, IMPS04 results are larger than those of IMPS19. This also happens in the Etna's volcanic region, even if a more recent study dealing with the hazard assessment for this area can be actually found in Azzaro et al. (2016).

Figure 5 quantifies the size of the area, in the two hazard maps, associated to each MCS grade, in both percentage (i.e., relatively to the Italian inland surface, computed as the number of grid points corresponding to the MCS grade over the total number of points; left axis), and absolute terms (i.e., square kilometers; right axis). It is shown that, for each grade, the corresponding fraction of Italy according to the PSHA results based on the two source models is quite comparable. More specifically, earthquakes with grade equal to or larger than IX are found in about $15 \%$ of the national territory in the case of IMPS19 (as also discussed before) and 12\% in the case of IMPS04. The same can be stated for the moderate-to-high hazardous regions: indeed, grade VII is found in about $30 \%$ of Italy in both the IMPS04 and IMPS19 hazard maps, whereas MCS VIII pertains to 35\% and $44 \%$, respectively. A slightly more evident difference is found in the case of MCS VI. Such a grade corresponds to about $13 \%$ of the country according to IMPS04, whereas it approaches to zero in the case of IMPS19. One of the reasons of these differences may be that MPS04 sources do not cover the whole Italy (i.e., there's no background seismicity), as the MPS19 grid-seismicity model does. For example, MCS VI is found in northern Italy and part of Apulia region, outside MPS04 sources (see Fig. 4a), whereas, in the same areas, it is MSC VII according to IMPS19 (Fig. 4b). 
What discussed so far shows that the IMPS19 hazard map is in a good agreement with the IMPS04 counterpart although source models, referred seismic catalogues and some propagation models ${ }^{1}$ (i.e., input models) at the base of the two maps are different. However, it is worthwhile noting that such an agreement between the two models considered herein is not found when the seismic hazard in terms of spectral pseudo-accelerations is compared. ${ }^{2}$ It is also to note that the comparison herein discussed should not be seen as any kind of validation of the results, yet it is intended only as informative; i.e., it by no means aims at providing a judgment. It has been extensively discussed elsewhere that the evaluation of hazard maps requires to compare them against ground motion observations in the years, an issue that, for large return periods (i.e., rare events) is hard, to say the least (e.g., Iervolino 2013; Iervolino et al. 2017).

\section{Conclusions}

Macroseismic intensity describes earthquakes' effects on communities, structures and environment. It may be used right after an earthquake for rapid loss assessment or, for example, in scenario-based risk analyses aimed at the evaluation of mitigations actions or for emergency planning purposes. Also, it may serve to characterize large-scale structural vulnerability on an empirical basis, or to have proxies for the event magnitude and the ground shaking in those areas where the seismic monitoring network is not dense or even absent. Therefore, it may be useful to derive, by means of PSHA, countrywide probabilistic seismic hazard maps providing the $M S$ intensity (discrete) grade which is observed or exceeded with a return period of interest.

With reference to Italy, at least three studies dealing with PSHA in macroseismic intensity at the national scale can be found in literature, the most recent of which dates more than a decade ago. They developed the map of the intensity grades, according to the Mercalli-Cancani-Sieberg scale, that have ten percent probability of being exceeded in fifty years.

Herein a $M S$ intensity hazard assessment study for Italy based on a recent grid-seismicity model was presented. The seismicity parameters were derived based on a conversion relationship between moment magnitude and the expected epicentral intensity. Results, that were obtained via PSHA and refer to the MCS grades corresponding to four return periods, were presented and, for each MCS grade, the map of the minimum return period causing its occurrence or exceedance was also discussed. Finally, the $475 \mathrm{yr}$ return period hazard map based on the grid-seismicity source model was compared to the analogous map provided by the reference PSHA study in $M S$ intensity for Italy. The main conclusions are recalled in the following.

- Given the return period, the lowest MCS grades pertain to Sardinia Island, part of Apulia, western Sicily and northern Italy. In the most hazardous area, that is, along the

\footnotetext{
${ }^{1}$ The propagation model of Pasolini et al. (2008), used in this study, is also employed within the logic tree used by Gomez Capera et al. (2010).

${ }^{2}$ Hazard maps for two spectral accelerations with the same return periods considered in this study based on MPS19 and MPS04 source model can be found in Chioccarelli et al. (2021) and Iervolino et al. (2018), respectively.
} 
Apennine mountain chain in central and southern Italy, MCS IX has a return period of $475 y r$.

- Considering $T_{r}=50 y r$, a MCS equal to or larger than VI corresponds to about $60 \%$ of the considered grid points (taken individually). In the case of $T_{r}=475 y r$, MCS VII and VIII correspond to about $30 \%$ and $44 \%$ of the points, respectively. Similar percentages, yet for the larger grades, were found for $T_{r}=975 y r$, being $37 \%$ for MCS VIII and $41 \%$ for MCS IX. As pertaining to $T_{r}=2475 y r$, MCS IX was still found for about $40 \%$ of the grid points, whereas it is $26 \%$ for MCS X.

- Anywhere in Italy, earthquakes of grade equal to or larger than IV have a return period lower than $50 y r$, whereas those of MCS intensity equal to or larger than XI have a return period longer than $2475 y r$. Along the Apennine mountain chain, earthquakes with grade equal to or larger than IX and X occur, on average, every 475 and $2475 y r$, respectively.

- The comparison between IMPS04 results and those presented in this paper shows that the MCS hazard maps from the two studies are generally comparable, and equivalent in more than half of Italy. IMPS04 results are lower than those found in this study mostly in the areas outside the zones of the source model used in IMPS04, whereas they are comparatively larger in part of Sicily and northwest area.

Hazard maps discussed in this study are provided with the paper as supplemental material.

Acknowledgements Authors are grateful to Dr. Aybige Akinci (Istituto Nazionale di Geofisica e Vulcanologia, Rome, Italy) and the anonymous reviewer for the helpful comments which helped in improving the quality of the manuscript.

Funding The study presented in this article was developed within the activities of the ReLUIS-DPC 201920121 research program, funded by Presidenza del Consiglio dei Ministri-Dipartimento della Protezione Civile (DPC).

Availability of data and material Hazard maps, for the four return periods shown in the study, are available at http://wpage.unina.it/iuniervo/papers/MPS19_MCS_hazard_maps.xlsx.

Code availability The REASSESS software, used for hazard calculations, is available at http://wpage.unina. it/iuniervo/doc_en/REASSESS.htm for research purposes.

\section{Declarations}

Conflict of interest The authors declare that they have no conflict of interest.

Open Access This article is licensed under a Creative Commons Attribution 4.0 International License, which permits use, sharing, adaptation, distribution and reproduction in any medium or format, as long as you give appropriate credit to the original author(s) and the source, provide a link to the Creative Commons licence, and indicate if changes were made. The images or other third party material in this article are included in the article's Creative Commons licence, unless indicated otherwise in a credit line to the material. If material is not included in the article's Creative Commons licence and your intended use is not permitted by statutory regulation or exceeds the permitted use, you will need to obtain permission directly from the copyright holder. To view a copy of this licence, visit http://creativecommons.org/licenses/by/4.0/. 


\section{References}

Albarello D, Bosi V, Bramerini F et al (2000) Carte di pericolosità sismica del territorio nazionale. Quad Di Geofis 12:1-7

Albarello D, Bramerini F, D'Amico V et al (2002) Italian intensity hazard maps: a comparison of results from different methodologies. Boll Di Geofis Teor Ed Appl 43:249-262

Albarello D, D’Amico V, Gasperini P, et al (2007) Nuova formulazione delle procedure per la stima dell'intensità macrosismica da dati epicentrali o da risentimenti in zone vicine. Progetto DPC-INGV S1. http://esse1.mi.ingv.it/d10.html

Ambraseys NN (1985) Intensity-attenuation and magnitude-intensity relationships for Nothwest European earthquakes. Earthq Eng Struct Dyn 13:733-778. https://doi.org/10.1002/eqe.4290130604

Azzaro R, D'Amico V, Tuvè T (2011) Estimating the magnitude of historical earthquakes from macroseismic intensity data: new relation-ships for the volcanic region of Mount Etna (Italy). Seismol Res Lett 82:533-544. https://doi.org/10.1785/gssrl.82.4.533

Azzaro R, D’Amico S, Tuvè T (2016) Seismic hazard assessment in the volcanic region of Mt. Etna (Italy): a probabilistic approach based on macroseismic data applied to volcano-tectonic seismicity. Bull Earthq Eng 14:1813-1825. https://doi.org/10.1007/s10518-015-9806-2

Boschi E, Guidoboni E, Ferrari G et al (2000) Catalogue of strong Italian earthquakes from 461 B.C. to 1997. Ann Geophys 43:609-868. https://doi.org/10.4401/ag-3668

C.S.LL.PP. (2018) Decreto Ministeriale: Norme tecniche per le costruzioni, Gazzetta Ufficiale della Repubblica Italiana, n. 42, 20 febbraio, Suppl. Ordinario n. 8. Ist. Polig. e Zecca dello Stato S.p.a., Rome (in Italian)

Camassi R, Stucchi M (1997) NT4.1: un catalogo parametrico di terremoti di area italiana al di sopra della soglia del danno. Cons Naz delle Ric Naz per la Dif dai Terremoti (CNR-GNDT), Milano, Italy $86 \mathrm{pp}$

CEN (2004) European Committee for Standardisation. Eurocode 8: design provisions for earthquake resistance of structures, part 1.1: general rules, seismic actions and rules for buildings, prEN 1998-1

Chioccarelli E, Cito P, Iervolino I, Giorgio M (2019) REASSESS V2.0: software for single- and multisite probabilistic seismic hazard analysis. Bull Earthq Eng 17:1769-1793. https://doi.org/10.1007/ s10518-018-00531-x

Chioccarelli E, Cito P, Iervolino I, Visini F (2021) Sequence-based hazard analysis for Italy considering a grid seismic source model. Ann Geophys 64:SE214. https://doi.org/10.4401/ag-8586

Faenza L, Michelini A (2010) Regression analysis of MCS intensity and ground motion parameters in Italy and its application in ShakeMap. Geophys J Int 180:1138-1152. https://doi.org/10.1111/j. 1365-246X.2009.04467.x

Giovinazzi S, Lagomarsino S (2004) A macroseismic method for the vulnerability assessment of buildings. In: 13th world conference on earthquake engineering, pp 1-6

Gomez Capera AA (2007) Seismic hazard map for the Italian territory using macroseismic data. Earth Sci Res J 10:67-90. https://doi.org/10.1126/science.113.2930.3

Gomez Capera AA, D'Amico V, Meletti C et al (2010) Seismic hazard assessment in terms of macroseismic intensity in Italy: a critical analysis from the comparison of different computational procedures. Bull Seismol Soc Am 100:1614-1631. https://doi.org/10.1785/0120090212

Gomez-Capera AA, D'Amico M, Lanzano G et al (2020) Relationships between ground motion parameters and macroseismic intensity for Italy. Bull Earthq Eng 18:5143-5164. https://doi.org/10.1007/ s10518-020-00905-0

Grünthal G (1998) European Macroseismic Scale 1998. Cah du Cent Eur Gèodynamiqueet Seismol

Gruppo di Lavoro (2004) Catalogo Parametrico dei Terremoti Italiani, versione 2004 (CPTI04), INGV, Bologna, Italy. http://emidius.mi.ingv.it/CPTI/

Gutenberg B, Richter CF (1944) Frequency of earthquakes in California. Bull Seismol Soc Am 34:185188. https://doi.org/10.1785/BSSA0340040185

Iervolino I (2013) Probabilities and fallacies: why hazard maps cannot be validated by individual earthquakes. Earthq Spectra 29:1125-1136. https://doi.org/10.1193/1.4000152

Iervolino I, Chioccarelli E, Giorgio M et al (2015) Operational (short-term) earthquake loss forecasting in Italy. Bull Seismol Soc Am 105:2286-2298. https://doi.org/10.1785/0120140344

Iervolino I, Giorgio M, Cito P (2017) The effect of spatial dependence on hazard validation. Geophys J Int 209:1363-1368. https://doi.org/10.1093/gji/ggx090

Iervolino I, Chioccarelli E, Giorgio M (2018) Aftershocks' effect on structural design actions in Italy. Bull Seismol Soc Am 108:2209-2220. https://doi.org/10.1785/0120170339 
Lanzano G, Luzi L, D’Amico V et al (2020) Ground motion models for the new seismic hazard model of Italy (MPS19): selection for active shallow crustal regions and subduction zones. Bull Earthq Eng 18:3487-3516. https://doi.org/10.1007/s10518-020-00850-y

Magri L, Mucciarelli M, Albarello D (1994) Estimates of site seismicity rates using ill-defined macroseismic data. Pure Appl Geophys 143:617-632

Mc Guire RK (2004) Seismic hazard and risk analysis. Earthquake Engineering Research Institute, Oakland, CA

Meletti C, Patacca E, Scandone P (2000) Construction of a seismotectonic model: the case of Italy. Pure Appl Geophys 157:11-35. https://doi.org/10.1007/978-3-0348-8415-0_2

Meletti C, Galadini F, Valensise G et al (2008) A seismic source zone model for the seismic hazard assessment of the Italian territory. Tectonophysics 450:85-108. https://doi.org/10.1016/j.tecto.2008.01.003

Meletti C, Marzocchi W, D’Amico V et al (2021) The new Italian seismic hazard model (MPS19). Ann Geophys 64:1-29. https://doi.org/10.4401/ag-8579

Michelini A, Faenza L, Lanzano G et al (2019) The new shakemap in Italy: progress and advances in the last 10 yr. Seismol Res Lett 91:317-333. https://doi.org/10.1785/0220190130

Mucciarelli M, Peruzza L, Caroli P (2000) Tuning of seismic hazard estimates by means of observed site intensities. J Earthq Eng 4:141-159. https://doi.org/10.1080/13632460009350366

Musson RMW, Grünthal G, Stucchi M (2010) The comparison of macroseismic intensity scales. J Seismol 14:413-428. https://doi.org/10.1007/s10950-009-9172-0

Pasolini C, Albarello D, Gasperini P et al (2008) The attenuation of seismic intensity in Italy, part II: modeling and validation. Bull Seismol Soc Am 98:692-708. https://doi.org/10.1785/0120070021

Reiter L (1990) Earthquake hazard analysis: issues and insights. Columbia University Press, New York

Rovida A, Locati M, Camassi R et al (2020) The Italian earthquake catalogue CPTI15. Bull Earthq Eng 18:2953-2984. https://doi.org/10.1007/s10518-020-00818-y

Sandron D, Renner G, Rebez A, Slejko D (2014) Early instrumental seismicity recorded in the eastern Alps. Boll Di Geofis Teor Ed Appl 55:755-788. https://doi.org/10.4430/bgta0118

Sibol MS, Bollinger GA, Birch JB (1987) Estimation of magnitudes in central and eastern North America using intensity and felt area. Bull Seismol Soc Am 77:1635-1654. https://doi.org/10.1785/BSSA0 770051635

Sieberg A (1930) Geologie Der Erdbeben. Handb Der Geophys 2:552-555

Slejko D, Peruzza L, Rebez A (1998) Seismic hazard maps of Italy. Ann Geophys 41:183-213. https://doi. org/10.4401/ag-4327

Stucchi M, Meletti C, Montaldo V et al (2011) Seismic hazard assessment (2003-2009) for the Italian building code. Bull Seismol Soc Am 101:1885-1911. https://doi.org/10.1785/0120100130

Visini F, Pace B, Meletti C et al (2021) Earthquake rupture forecasts for the mps 19 seismic hazard model of Italy. Ann Geophys 64:SE220. https://doi.org/10.4401/ag-8608

Wald DJ, Quitoriano V, Heaton TH et al (1999a) TriNet "ShakeMaps": rapid generation of peak ground motion and intensity maps for earthquakes in southern California. Earthq Spectra 15:537-555. https:// doi.org/10.1193/1.1586057

Wald DJ, Quitoriano V, Heaton TH, Kanamori H (1999b) Relationships between peak ground acceleration, peak ground velocity, and modified Mercalli intensity in California. Earthq Spectra 15:557-564. https://doi.org/10.1193/1.1586058

Publisher's Note Springer Nature remains neutral with regard to jurisdictional claims in published maps and institutional affiliations. 